\title{
Indentifikasi dinamika sumber tremor vulkanik gunungapi Raung berdasarkan analisis fraktal
}

\author{
Arin Wildani ${ }^{1}$, Chairatul Umamah ${ }^{1}$, Agus Budiyono ${ }^{1}$ \\ ${ }^{1}$ Prodi Pendidikan Fisika, Universitas Islam Madura, Kabupaten Pamekasan 69317, Indonesia \\ E-mail: arinwildani@gmail.com; ieera.kireina@gmail.com; abybudiyono@gmail.com
}

Received: 1710 2017. Revised: 1701 2018. Accepted: 02032018

\begin{abstract}
Abstrak
Tremor vulkanik merupakan salah satu gelombang seismik yang biasa terekam di sekitar gunungapi dan dapat menjadi indikasi akan terjadinya suatu letusan. Pengetahuan secara kuantitatif mengenai parameter fisis tremor vulkanik dapat melengkapi dalam memprediksi terjadinya suatu letusan. salahsatu parameter fisis tremor vulkanik yaitu nilai dimensi fraktal. Pada penelitian ini digunakan rekaman data seismik tremor vulkanik Gunungapi Raung dari tahun 2011- 2013. Berdasarkan hasil seleksi data maka didapatkan 21 kejadian tremor vulkanik Gunungapi Raung. Pada penelitian dilakukan analisis fraktal dengan merekonstruksi diagram attraktor dari tremor vulkanik menggunakan teorema delay embedding. Analisis data dilakukan dengan menentukan delay time menggunakan Mutual Information dan dimensi embedding dari masing-masing kejadian tremor vulkanik menggunakan False Nearest Neighbour (FFN). delay time tremor vulkanik gunungapi Raung didapatkan sebesar 0,085 s dan dimensi embedding tremor vulkanik gunungapi Raung didapatkan berada dalam rentan 4-5. Dimensi fraktal tremor vulkanik gunungapi berada dalam range $1,81-2,15$. Perubahan secara temporal nilai dimensi fraktal mengindikasikan bahwa tremor vulkanik disebabkan oleh sistem non linier didalam pipa konduit berbentuk silinder.
\end{abstract}

Kata Kunci: tremor vulkanik; gunungapi Raung; analisis fractal; teorema delay embedding

\section{The identification of dynamic souce volcanic tremor at Mountain Raung based on fractal analysis}

\begin{abstract}
Volcanic tremor is one of the usual seismic waves recorded around the volcano and can be an indication of the occurrence of an eruption. Quantitative knowledge of the physical parameters of volcanic tremor can be complementary in predicting the occurrence of an eruption. one of the physical parameters of volcanic tremors is the fractal dimension value. This study was conducted to determine the dynamics of volcanic volcanic source Raung volcano based on fractal analysis. This research used the data of seismic volcanic tremor of volcanic volcano from 2011 to 2013. Based on the result of data selection, there are 21 volcanic volcano tremor events of Raung volcano. In the research, fractal analysis was done by reconstructing the attractor diagram of volcanic tremor using delay embedding theorem. Data analysis was performed by determining the delay time using Mutual Information and the embedding dimension of each volcanic tremor event using False Nearest Neighbor (FFN). the delay time volcanic volcanic tremor of Raung volcano was obtained at $0.085 \mathrm{~s}$ and the embedding dimension of Volcanic Volcano Raung volcano was found to be susceptible to 4-5. The volcanic volcanic fractal dimension of volcano is in the range of 1.81 to 2.15. The value changes in the time function. The temporal dimension of fractal dimension values indicates that volcanic volcanic tremor of Raung volcano is caused by non-linear system inside conduit pipe. The nonlinear system is related to the flow of magma to the surface due to the pressure is not constant.
\end{abstract}

Keywords: volcanic tremor; Raung volcano; fractal analysis; delay embedding theorem 


\section{PENDAHULUAN}

Gunungapi Raung merupakan salahsatu gunungapi aktif yang termasuk dalam deretan gunungapi Indonesia. Secara geografis puncak gunung Raung terletak pada posisi $8^{\circ} 07^{\prime} 30^{\prime \prime}$ LS dan $114^{\circ} 02^{\prime} 30^{\prime \prime}$ BT dengan tinggi puncaknya 3332 meter diatas permukaan laut. Secara administratif gunung Raung termasuk dalam tiga wilayah Kabupaten, yaitu Bondowoso, Banyuwangi, dan Jember Propinsi Jawa Timur. Kegiatan gunung Raung umumnya dicirikan oleh hembusan asap kawah berwarna putih tipis dengan ketinggian berkisar antara 50 hingga 75 meter dari puncak (Wildani et al, 2012). Berdasarkan sejarah letusannya gunung Raung beberapa kali memiliki letusan besar hingga memakan korban jiwa. Letusan gunungapi Raung tidak kontinyu, berdasarkan sejarah letusan terdapat jeda sekitar 3-5 tahun setiap terjadi letusan besar.

Meskipun aktifitas gunungapi Raung dipantau oleh oleh Pusat Vulkanologi dan Mitigasi Bencana Geologi (PVMBG) melalui pos pemantauan gunungapi Raung yang terletak di Desa Sragi Kecamatan Singojuruh Kabupaten Banyuwangi. Pemantauan yang dilakukan berupa pemantauan visual, kegempaan dan deformasi. Pemantauan tersebut belum mencakupi penelitian secara menyeluruh mengenai aktifitas internal dari gunungapi Raung. Aktifitas internal suatu gunungapi meliputi aktifitas kegempaan yang bersifat impulsif dan aktifitas kegempaan yang tidak impulsif atau disebut tremor vulkanik. Penelitian ini menganalisis tremor vulkanik gunungapi Raung.

Tremor vulkanik merupakan salahsatu aktivitas seismik suatu gunungapi yang yang berbeda dari yang aktifitas seismik lainnya. beberapa parameter fisis yang unik seperti puncak frekuensi yang tajam atau puncak frekuensi yang harmonik merupakan karakteristik dari tremor vulkanik. Secara umum sumber utama tremor vulkanik yaitu pergerakan magma yang berfase zat alir (fluida) didalam tubuh gunungapi. Meskipun sumber utama tremor vulkanik sudah diketahui namun proses yang terjadi didalam tubuh setiap gunungapi berbeda-beda sehingga masing-maisng gunungapi memiliki karakteristik tersendiri.

Keunikan dari tremor vulkanik menimbulkan ketertarikan kalangan peneliti untuk mengetahui karakteristik, lokasi dan mekanisme sumber tremor vulkanik dari suatu gunungapi. pemahaman tremor vulkanik suatu gunungapi secara rinci akan melengkapi data untuk memprediksi waktu dan pola erupsi dari suatu gunungapi.

Beberapa penelitian dengan pendekatan empiris dan pendekatan analisis fisis dan matematis telah dilakukan untuk menjelaskan mekanisme sumber tremor vulkanik suatu gunungapi. Pendekatan yang dilakukan mencakup geometri ruang, sifat fisika-kimia magma, hingga sifat fisika batuan di sekitar magma. Beberapa penelitian tersebut antara lain tremor vulkanik disebabkan akibat impedansi aliran fluida di dalam pipa konduit. Selain itu juga disebutkan bahwa tremor bisa berasal dari eksitasi aliran fluida yang tidak stabil, dimana frekuensi tremor yang dihasilkan dipengaruhi oleh massa jenis magma, tekanan dan sifat elastik dari batuan di sekitar magma (Lumbanraja, 2014). Tremor vulkanik juga disebabkan oleh proses non linier didalam saluran magma berbentuk silinder, dan diduga dihasilkan oleh aliran magma yang mempunyai dua fase fluida yaitu fase gas dan fase cair (Wildani et al., 2012).

Penelitian dengan menganalisis pola perubahan spektrum dari tremor vulkanik gunungapi telah banyak dilakukan antara lain analisis spektral tremor vulkanik gununapi semeru dimana didapatkan bahwa tremor vulkanik gunungapi Semeru diduga disebabkan aliran gas dalam pipa organa terbuka (Wildani et all, 2009). Selain penelitian mengenai kandungan frekuensi tremor vulkanik, vulkanik gunugapi juga telah banyak dilakukan. Penentuan dimensi fraktal merupakan analisis non linier untuk mengidentifikasi dinamika dari sumber tremor vulkanik suatu gunungapi bersifat kaotik atau tidak (Konstantinou et al., 2013). Beberapa penelitian mengenai analisis fraktal yang sudah dilakukan di beberapa gunungapi antara lain analisis fraktal tremor vulkanik yang terekam di gunung Semeru (Maryanto \& Mulyana, 2008)(Konstantinou et al., 2013) dan analisis fraktal tremor vulkanik yang terekam di gunung Sakurajima (Maryanto, Santosa, Mulyana, \& Hendrasto, 2011). Dari semua hasil penelitian tersebut didapatkan nilai dimensi fraktal yang rendah untuk tremor vulkanik. 
Jurnal Pendidikan Fisika dan Keilmuan (JPFK), 4 (1), 2018 - 25

Arin Wildani, Chairatul Umamah, Agus Budiyono

Tabel 1. Lokasi stasiun seismik gunung Raung

\begin{tabular}{ccccc}
\hline \multirow{2}{*}{ Stasiun } & \multirow{2}{*}{ Sifat } & \multicolumn{3}{c}{ Posisi geografis } \\
\cline { 3 - 5 } & & Lintang Selatan & Bujur Timur & Ketinggian(m) \\
\hline Raung & Permanen & $08^{0} 09^{\prime} 19.8^{\prime \prime}$ & $114^{0} 07^{\prime} 17.0^{\prime \prime}$ & 1264 \\
\hline Sumberwringin & Temporer & $08^{0} 02^{\prime} 38.0^{\prime \prime}$ & $114^{0} 01^{\prime} 26.5^{\prime \prime}$ & 1319 \\
\hline Mlaten & Temporer & $08^{0} 04^{\prime} 41.2^{\prime \prime}$ & $114^{0} 07^{\prime} 55.2^{\prime \prime}$ & 1676 \\
\hline
\end{tabular}

Penelitian ini menekankan pada menit. Waktu sampling yang digunakan 100 analisis fraktal dari tremor vulkanik cuplikan per detik. Hal tersebut berarti dalam gunungapi Raung. Analisis fraktal dilakukan dengan cara menggambarkan diagram phasespace (aktraktor) dari data deret waktu tremor vulkanik gunungapi Raung. Penggambaran diagram aktraktor dilakukan dengan menggunakan teorema delay embedding. Dimensi fraktal tremol vulkanik pada penelitian ini ditentukan dengan menggunakan metode dimensi korelasi.

\section{METODE}

Penelitian ini menggunakan data sekunder rekaman seismik gunungapi Raung dari tahun 2011 sampai tahun 2013. Data tersebut didapatkan dari Pusat Vulkanologi dan Mitigasi Bencana Geologi (PVMBG), Bandung, Jawa Barat. Data tersebut di transmisikan dari pos pemantauan gunung Raung di Banyuwangi, Jawa Timur. Data tersebut mencakup semua hasil rekaman dari tiga stasiun seismik gunung Raung, tabel 1 memperlihatkan lokasi stasiun seismik gunung Raung. Data-data yang didapatkan merupakan kumpulan sinyal seismik yang berbentuk data digital. Pembacaan data dilakukan dengan menggunakan perangkat lunak LS7_WVE. Dalam satu jendela pembacaan, data dibaca dengan durasi satu satu detik direkam sebanyak 100 data.

Pada dasarnya program LS7_WVE ini merupakan perangkat lunak untuk membaca data hasil konversi rekaman analog ke dalam rekaman digital melalui perangkat keras Datamark. Data kejadian didefinisikan dengan nama file yang memuat tahun, bulan, tanggal, hari, jam dan menit secara berurutan. Misalkan kejadian yang didapat adalah 13111012.30, maka kejadian tersebut terjadi pada tanggal 10 November 2013, Pukul 12.30 WIB. Seleksi data dilakukan pada tiga stasiun seismik yaitu Raung, Mlaten dan Sumberwringin.

Alur penelitian seperti pada gambar1. Langkah pertama yaitu seleksi data sinyal tremor vulkanik dengan kenampakan jelas, seleksi data dilakukan pada seluruh data rekaman seismik gunungapi Raung. Data seismik yang didapatkan sudah mempunyai karakteristik yang sama pada semua stasiun, karena perangkat keras yang digunakan untuk merekam data seismik memiliki tipe dan spesifikasi yang sama serta desain pengukuran yang sama serta terkalibrasi yaitu seismometer 1 komponen tipe LC-4.

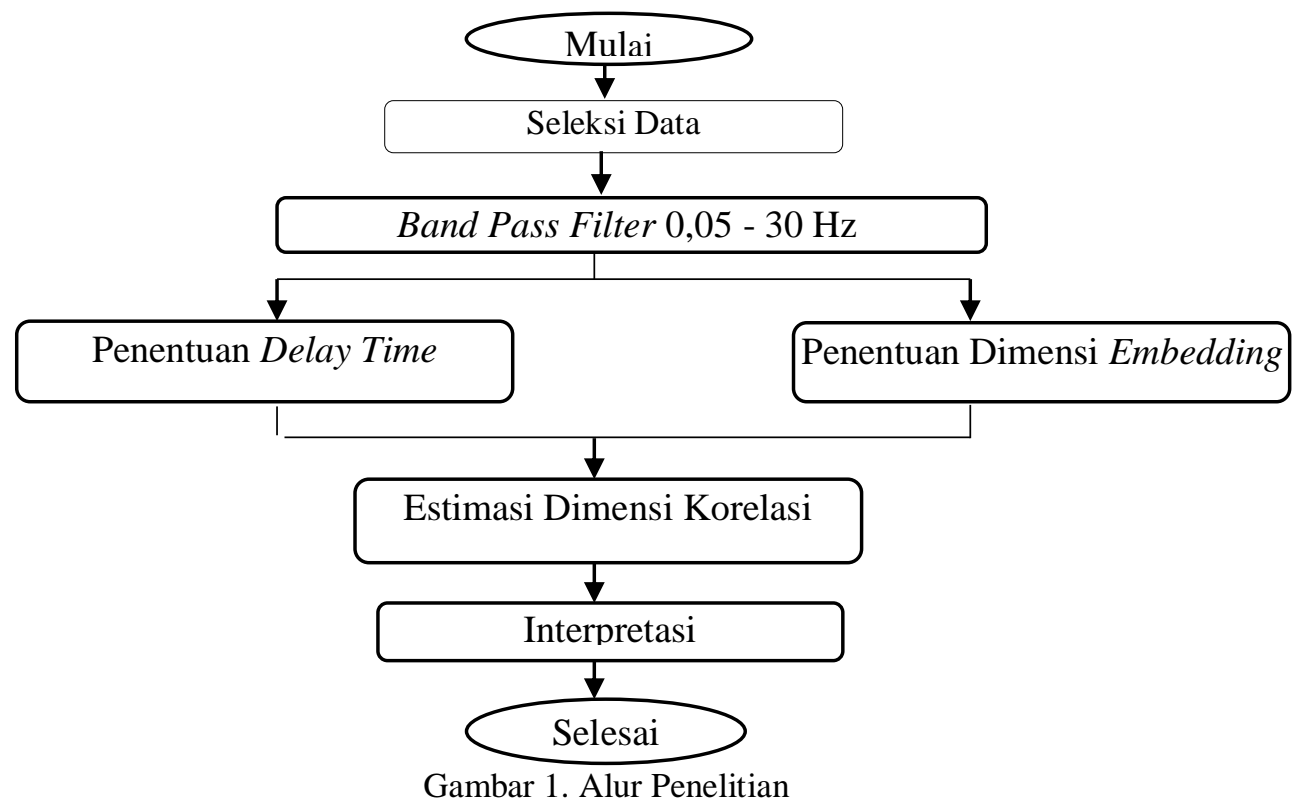

Copyright (C) 2018, Jurnal Pendidikan Fisika dan Keilmuan (JPFK) ISSN 2442-8868 (print), ISSN 2442-904X (online) 


\section{HASIL DAN PEMBAHASAN}

Langkah selanjutnya yang dilakukan yaitu menyaring sinyal seimik dengan Band Pass Filter untuk menghilangkan frekuensifrekuensi diluar jangkauan yang diharapkan. Jangkauan frekuensi yang diharapkan yaitu antara $0,05 \mathrm{~Hz}$ s/d $30 \mathrm{~Hz}$ dimana frekuensi dibawah nilai $0,05 \mathrm{~Hz}$ dianggap sebagai noise Delay time ditentukan dengan menggunakan metode Mutual Information (MI) dan delay time dipilih nilai minimum pertama. Mutual Information (MI) dari data runtun waktu $X_{i}(i=1,2,3, \ldots M)$ didefinisikan sebagai berikut:

$M I(X, Y)=\sum_{i} \Sigma_{j} p_{x y}\left(i_{i}, j\right) \log \frac{p_{x y}(i, j)}{p_{x}(i) p_{y}(j)}(1)$

dimana $p_{x}(i)$ merupakan probability distribution dari $X_{i}$ dan $p_{y}(j)$ merupakan probability distribution dari $Y_{j}(j=\alpha, \alpha+1, \ldots$, $\alpha+M)$. Gambar 1 merupakan delay time tremor vulkanik gunung Raung didapatkan 0,08 sekon (timelag dikalikan dengan sampling rate)(Fraser \& Swinney, 1986).

Perilaku kaotik dalam diagram attraktor ditunjukkan dengan tidak adanya orbit yang tumpang tindih, oleh karena itu dimensi embedding yang digunakan untuk rekonstruksi diagram attraktor harus sesuai. Metode yang digunakan untuk menentukan dimensi embedding yang sesuai yaitu False Nearest Neighbour (FNN)(Dolu, 1999).

FNN terjadi pada suatu kondisi dimana jarak antara titik-titik (data) pada saat dimensi tertentu, jauh melampaui tresshold pada saat titik-titik tersebut berada di dimensi lainnya. Asumsikan bahwa titik $x^{a}$ dan $x^{b}$

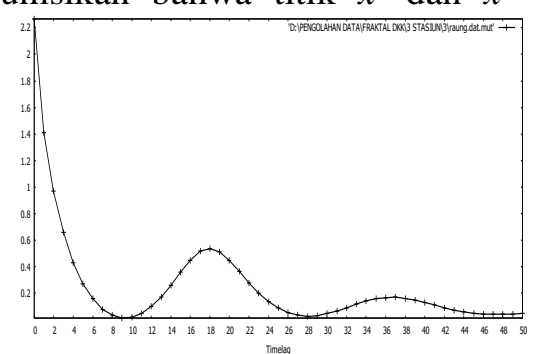

saling berdekatan dalam diagram attraktor. Jarak antara dua titik tersebut yaitu $\left|x^{a}-x^{b}\right|$, untuk mengetahui apakah kedua titik tersebut termasuk FNN maka dapat dilakukan dengan membandingkan jarak Euclidian kedua titik tersebut di dua dimensi embedding berturut-turut misalnya dimensi embedding $d$ dan $d+1$. Jarak Euclidian dua titik untuk dimensi embedding $m$ dan delay time $\tau$ sebagai berikut;

$R_{d}^{2}=\sum_{m=0}^{d-1}\left[s^{a}(t+m \tau)-s^{b}(t+m \tau)\right]^{2}(2)$

jika dimensi berpindah dari $d$ ke $d+1$ maka koordinat yang baru menjadi $s(t+d \tau)$, sehingga jarak Euclidean dua titik dalam dimensi yang baru $d+1$ menjadi;

$$
R_{d+1}^{2}=R_{d}^{2}(t)+\left|s^{a}(t+d \tau)-s^{b}(t+d \tau)\right|^{2}
$$

Jarak relatif antara dua titik di dimensi $d$ dan $d+1$ sebagai berikut:

$\sqrt{\frac{R_{d+1}^{n}-R_{d}^{a}}{R_{d}^{3}}}=\frac{\left|s^{a}(t+d \tau)-s^{b}(t+d \tau)\right|}{R_{d}}$

Jika perbandingan jarak pada persamaan 5 lebih besar dari $s$, dimana $s$ besarnya ditentukan, maka Nearest Neighbour dengan jumlah dimensi yang digunakan merupakan FNN. sehingga proses akan terus diiterasikan lagi dengan jumlah dimensi selanjutnya sampai nilai $\mathrm{FNN}=0$ (Konstantinou, 2004).

$\frac{\| s^{a}(t+d \tau)-d^{b}(t+d \tau) \mid}{R_{d}}>s$

Nilai $s$ untuk sistem non linier berharga 15. Gambar 2 memperlihatkan $\mathrm{FNN}=0$.

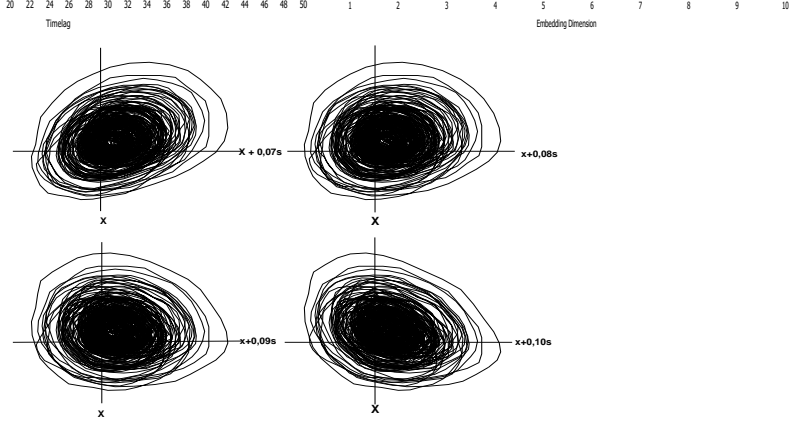

Gambar 2. Hasil analisis fraktal tremor vulkanik gunungapi Raung 


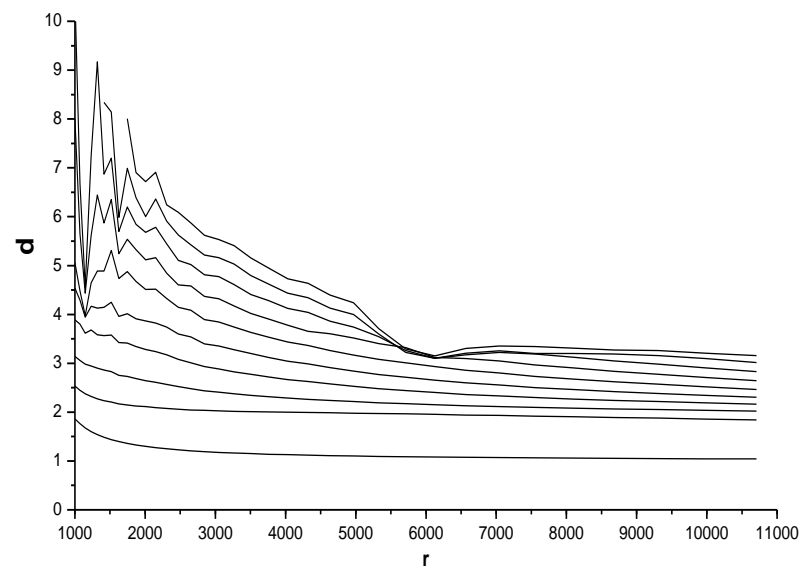

Gambar 3. Grafik hubungan dimensi korelasi dan $r$ tremor vulkanik menunjukan scalling region di sekitar $\mathrm{r}=5500-6500$ dan $\mathrm{d}=3,14$

Struktur fraktal sering ditemukan pada diagram attraktor dimana harga kuantitasi fraktalnya disebut dimensi fraktal. Penentuan dimensi fraktal dapat dihitung dengan metode dimensi korelasi $(d)$ sebagai berikut;

$d=\lim _{r \rightarrow 0} \frac{\ln (C(r))}{\ln (r)}$

dengan

$C(r)=\lim _{r \rightarrow 0} \frac{1}{N[N-1)} \sum_{i=1}^{N-1} \sum_{j=1}^{N} H\left(r-\left|\vec{x}_{1}-\vec{x}_{j}\right|\right)$
$H(s)=1$ jika $s>0$ dan $H(s)=0$ jika $s<0$. Dimensi embedding dan delay time yang digunakan yaitu dimensi embedding dan delay time yang didapatkan dari perhitungan sebelumnya. Gambar 3 memperlihatkan grafik hubungan antara $d$ dan $r$ dan daerah scalling region menunjukkan nilai dimensi fraktal. Gambar 2 menunjukkan diagram attraktor yang telah direkonstruksi dari tremor vulkanik dengan delay time yang berbedabeda yaitu $0,07 \mathrm{~s}, 0,08 \mathrm{~s}, 0,09 \mathrm{~s}$, dan $0,10 \mathrm{~s}$. Perbedaan delay time mempengaruhi rekonstruksi diagram attractor.

Tremor Vulkanik G.Raung 2011-2013

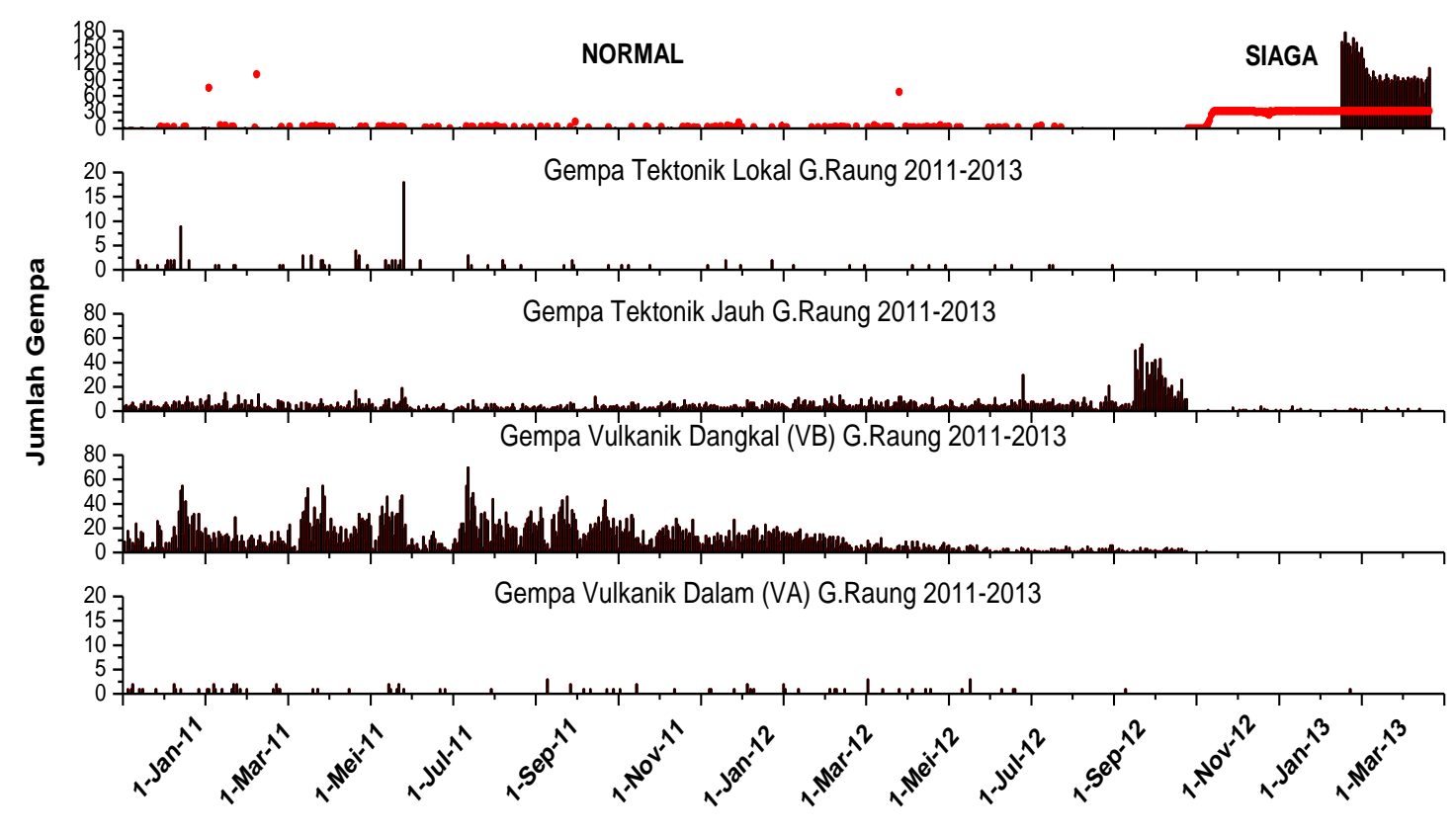

Gambar 4. Aktifitas kegempaan gunung Raung 
Jurnal Pendidikan Fisika dan Keilmuan (JPFK), 4 (1), 2018 - 28

Arin Wildani, Chairatul Umamah, Agus Budiyono

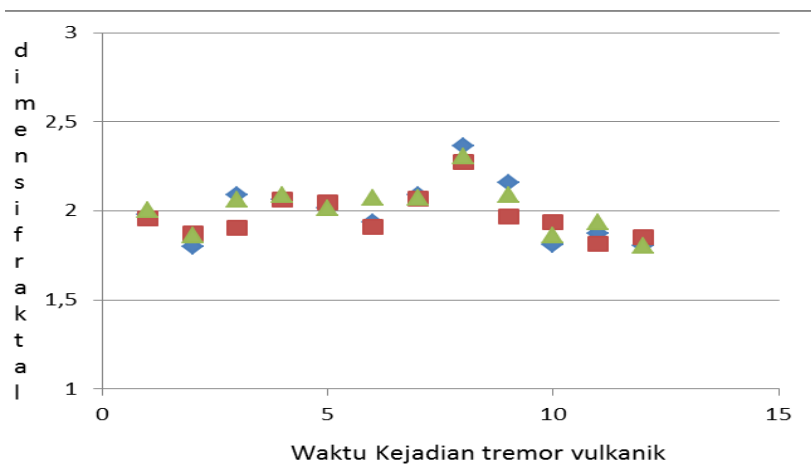

Gambar 5. Perubahan secara temporal nilai dimensi fraktal dari tiga stasiun seismik

Gambar 4 memperlihatkan seismisitas gunungapi Raung. Aktifitas kegempaan didominasi oleh gempa vulkanik dangkal. Kondisi tersebut mengindikasikan bahwa panjang pipa konduit relatif dekat dengan permukaan. Dalam rentan waktu tertentu memperlihatkan bahwa aktifitas gempa vulkanik dangkal menurun sementara gempa tremor meningkat. Dalam kondisi ini berarti magma mulai bergerak menuju permukaan. Pergerakan magma menuju permukaan ini menjadi sumber dari tremor vulkanik gunungapi Raung.

Analisis fraktal dilakukan pada rekaman dari tiga stasiun seismik gunung Raung. Perubahan dinamika titik-titik dalam diagram attraktor bisa menggambarkan variasi parameter fisis yang mengendalikan sistem non linier tersebut. Perubahan secara temporal dinamika titik-titik dalam diagram attraktor dapat dilihat dari perubahan dimensi fraktalnya. Pada penelitian ini perubahan secara temporal dimensi fraktal tremor vulkanik gunung Raung dapat dilihat pada tabel 2. Nilai dimensi fraktal tremor vulkanik gunung Raung berada dalam range 1,812,15. Nilai dimensi fraktal antar stasiun Raung, Mlaten dan Sumber wringin menunjukkan nilai yang tidak jauh berbeda hal ini menunjukkan bahwa sumber tremor vulkanik berasal dari sumber yang sama dan disebabkan oleh proses yang sama. Perbedaan nilai tersebut dapat disebabkan oleh noise dalam perpindahan energi dari sumber menuju seismometer. Perubahan dimensi fraktal secara temporal terlihat pada gambar 5 . Perubahan nilai dimensi fraktal tersebut menunjukan bahwa sumber tremor vulkanik gunungapi Raung bersifat chaos (acak). Hal ini berarti bahwa penyebab tremor vulkanik gunungapi Raung adalah sistem non linier dari aliran magma didalam pipa konduit gunungapi Raung.

Wildani dkk menyatakan bahwa sumber tremor vulkanik gunungapi Raung disebabkan oleh aliran magma dalam saluran pipa konduit berbentuk silinder akibat tekanan yang tidak konstan (Wildani et al., 2012). Selain itu tremor vulkanik gunungapi Raung juga disebbakan oleh perubahan parameter fisika yang statik (viskositas magma, panjang dan diameter saluran) ataupun parameter fisika yang dinamik (beda tekanan pada ujung-ujung saluran)

Tabel 2. Timelag, dimensi embedding dan dimensi fraktal 12 kejadian tremor vulkanik gunungapi Raung

\begin{tabular}{lcccccccccc}
\hline \multirow{2}{*}{ Waktu Kejadian } & \multicolumn{3}{c}{ Timelag } & \multicolumn{2}{c}{ Dimensi Embedding } & \multicolumn{2}{c}{ Dimensi Fraktal } \\
\cline { 2 - 9 } & Raung & Mlt & SW & Raung & Mlt & SW & Raung & MIt & SW \\
\hline 1211110910 & 9 & 12 & 12 & 5 & 6 & 5 & 2,08994 & 2,90455 & 2,06556 \\
\hline 1211111251 & 9 & 12 & 12 & 5 & 6 & 5 & 2,06556 & 2,06556 & 2,04581 \\
\hline 1211111536 & 9 & 10 & 11 & 4 & 5 & 4 & 2,01681 & 1,90897 \\
\hline 1211111811 & 9 & 12 & 13 & 5 & 5 & 4 & 1,93566 & 2,07454 \\
\hline 1211112135 & 9 & 11 & 12 & 5 & 5 & 4 & 2,08994 & 2,06691 \\
\hline 1211120103 & 9 & 10 & 12 & 5 & 5 & 4 & 2,36556 & 2,27541 \\
\hline 1211120426 & 9 & 10 & 12 & 5 & 5 & 4 & 2,15641 & 1,96571 \\
\hline 1211120709 & 9 & 11 & 12 & 4 & 5 & 4 & 1,80897 & 1,93406 \\
\hline 1211121044 & 9 & 11 & 11 & 5 & 6 & 5 & 1,87151 & 1,86247 \\
\hline 1211121630 & 9 & 10 & 10 & 5 & 5 & 5 & 1,80342 & 1,81711 \\
\hline
\end{tabular}




\section{SIMPULAN}

Dimensi fraktal tremor vulkanik berada dalam range $1,81-2,15$. Perubahan secara temporal nilai dimensi fraktal mengindikasikan bahwa tremor vulkanik disebabkan oleh sistem non linier didalam pipa konduit berbentuk silinder. Aliran magma didalam pipa konduit berbentuk silinder tersebut menjadi sumber dari tremor vulkanik gunungapi Raung.

\section{UCAPAN TERIMAKASIH}

Penelitian ini merupakan hibah penelitian dosen pemula yang didanai oleh anggaran DIPA direktorat jenderal penguatan riset dan pengembangan kementerian riset dan teknologi pendidikan tinggi. Penulis mengucapkan banyak terimakasih kepada pihak-pihak yang terlibat khususnya KEMENRISTEKDIKTI dan Pusat Vulkanologi dan Mitigasi Bencana Geologi (PVMBG).

\section{DAFTAR PUSTAKA}

Dolu, A. (1999). Analisis getaran non linier dan fenomena chaos pada solusi persamaan diferensial duffing. Kajian Teoritik Sistem Peredam Getaran Satu Derajat Kebebasan, 2.

Fraser, A. M., \& Swinney, H. L. (1986). Independent coordinates for strange attractors form mutual information. Phys. Rev. A.

KonstantinoU, K. I. (2004). Nonlinear Time Series Analysis of Volcanic Tremor EventsirRecorded at Sangay Volcano, Ecuador. Pure and Applied Geophysics, 161 , 145-163. https://doi.org/10.1007/s00024-0032432-y

Konstantinou, K. I., Perwita, C. A., Maryanto, S., Budianto, A., Hendrasto, M., \& Surono. (2013). Maximal Lyapunov exponent variations of volcanic tremor recorded during explosive and effusive activity at Mt Semeru volcano, Indonesia. Nonlinear Processes in Geophysics, 20(6), 1137-1145. https://doi.org/10.5194/npg-20-1137-

2013

Lumbanraja, W. (2014). Identifikasi Dinamika Magma Berdasarkan Analisis Tremor Vulkanik di Gunungapi Slamet Jawa Tengah. Tesis, 19(57), 55-61.

Maryanto, S., \& Mulyana, I. (2008). Temporal Change of Fractal Dimension of Explosion Earthquakes and Harmonic Tremors at Semeru Volcano, East Java, Indonesia , using Critical Exponent Method. International Journal of Engineering and Applied Sciences, 2(6), 537-541.

Maryanto, S., Santosa, D. R., Mulyana, I., \& Hendrasto, M. (2011). Fractal and Chaos Properties of Explosion Earthquakes Followed by Harmonic Tremor at Semeru Volcano, East Java, Indonesia, 2(7), 1-7.

Wildani, A., Maryanto, S., Gunawan, H., Triastuty, H., \& Hendrasto, M. (2012). ANALISIS NON LINIER TREMOR VULKANIK GUNUNGAPI RAUNG JAWA TIMUR - INDONESIA Oleh: Program Pasca Sarjana Jurusan Fisika ,.

Wildani, A., Maryanto, S., \& Susilo, A. (2009). Analisis Sinyal Seismik Tremor Harmonik Dan Tremor Spasmodik Gunungapi Semeru , Jawa Timur Indonesia. Jurnal Pemikiran Penelitian Pendidikan Dan Sains, 3(6), 140-150. 